\title{
The Role of Factors Associated With Apoptosis in Assessing Periodontal Disease Status
}

Heba Abuhussein, * Jill D. Bashutski, ${ }^{\dagger}$ Darya Dabiri, ${ }^{\dagger}$ Sindhu Halubai, ${ }^{\dagger}$ Mary Layher, ${ }^{\dagger}$ Christine Klausner, ${ }^{\dagger}$ Huwaida Makhoul, ${ }^{\dagger}$ and Yvonne Kapila ${ }^{\dagger}$

Background: Little is known about the release of apoptotic proteins during periodontal breakdown. This pilot study investigates the presence of factors associated with apoptosis in serum, saliva, and gingival crevicular fluid (GCF) and their association with periodontal disease severity and activity.

Methods: GCF, whole saliva, and serum were obtained from 47 adult patients with chronic periodontitis (CP) and 10 healthy controls. Clinical measurements, including probing depth (PD), clinical attachment level (CAL), and radiographs, were used to classify patients into healthy, mild, and moderate/severe CP groups. Enzyme-linked immunosorbent assays were used to measure apoptosis or DNA fragmentation in GCF and active caspase-3, soluble Fas (sFas), and sFas ligand ( $\mathrm{sFasL}$ ) in saliva and serum. Western immunoblotting was used to detect Fas, FasL, sFasL, and caspase-3 expression in GCF.

Results: DNA fragmentation was positively correlated with $\mathrm{PD}$ and CAL regardless of patient disease status $(P<0.001)$. sFas and sFasL were present in saliva and serum, but there were no differences between groups. In GCF, the greater odds of detecting Fas, sFasL, and caspase-3 increased with increasing PD and CAL $(P<0.05)$. In addition, sites with inflammation and PD $\geq 5 \mathrm{~mm}$ had significantly greater odds of exhibiting Fas, sFasL, and caspase- 3 expression compared with sites without inflammation and $\mathrm{PD}<5 \mathrm{~mm}$ $(P<0.05)$. Caspase-3 was not detected in saliva or serum. At the patient level, only FasL and disease status were significantly correlated $(P<0.05)$.

Conclusion: Factors associated with apoptosis were detected in GCF in patients with CP. J Periodontol 2014;85: 1086-1095.

\section{KEY WORDS}

Apoptosis; gingival crevicular fluid; periodontitis.

\footnotetext{
* School of Dentistry, King Abdulaziz University, Jeddah, Kingdom of Saudi Arabia.

$\dagger$ Department of Periodontics and Oral Medicine, School of Dentistry, University of Michigan, Ann Arbor, MI.
}

The mechanisms responsible for periodontal disease progression remain unclear. However, recent studies suggested that apoptosis may be one mechanism underlying the pathophysiology involved with the progression of periodontitis., ${ }^{1,2}$ Also known as "programmed cell death,"3 apoptosis plays a critical role in the regulation of the host immune response and inflammation and can be modulated by various stimuli, including cytokines, bacterial and viral infections, immune cells themselves, and changes in growth factors, nutrients, and the extracellular matrix. ${ }^{4}$

One of the best-defined apoptotic pathways is mediated by the death receptor Fas and Fas ligand (FasL) complex. The Fas receptor is expressed on many cell types that include gingival fibroblasts, skin keratinocytes, and $\mathrm{T}$ cells $^{5-7}$ Apoptotic cells are present in diseased gingiva. ${ }^{8}$ During cell apoptosis, a sequential activation of cysteine proteases, called caspases, plays a central role in the execution phase of apoptosis. Caspase- 3 is one of the key executor caspases that regulates a number of critical cellular substrates and when active has been easily detected in cells undergoing apoptosis. ${ }^{9}$ Eventually, the caspase cascade culminates in the cleavage of DNA into fragments, a hallmark of apoptosis. 
A number of apoptotic markers have been shown to increase in the presence of disease. Fas and FasL were found at higher levels in autoimmune diseases, ${ }^{10,11}$ atherosclerosis, coronary disease, ${ }^{12,13}$ cancer, ${ }^{14-16}$ rheumatoid arthritis, ${ }^{17}$ and hepatitis. ${ }^{18}$ Caspase-3, another hallmark of apoptosis, has also been detected in inflammatory diseases, including rheumatoid arthritis. ${ }^{18,19}$ In the periodontium, expression of apoptosis-associated genes were shown to increase when healthy gingival tissue was exposed to pathogenic periodontal bacteria. ${ }^{20}$ Furthermore, Fas and FasL were associated with chronic periodontitis (CP). ${ }^{21}$

There is a critical need for the development of more advanced diagnostic methods to predict the presence of more severely inflamed periodontal sites and to potentially determine the risk of an inactive site becoming active. Analysis of apoptotic markers in gingival crevicular fluid (GCF), saliva, and serum show potential for this application; however, studies in this area are lacking. The aim of this study is to determine whether DNA fragmentation and apoptosis-associated proteins from GCF, saliva, and serum were associated with periodontal disease status and whether these molecules could be used as markers to determine more severely inflamed sites, which could be a predictor of periodontal disease activity.

\section{MATERIALS AND METHODS}

A single-center cross-sectional study of patients with or without periodontal disease was conducted at the Michigan Center for Oral Health Research at the University of Michigan from 2006 to 2009 after University of Michigan Institutional Review Board approval was obtained. Fifty-seven adult patients (26 males and 31 females, aged 28 to 79 years; mean age: 52.45 years) were recruited from the surrounding community after giving written consent (Table 1). Participants were excluded from the study if they: 1) had <20 teeth; 2) were pregnant or suffered from metabolic bone diseases, autoimmune disease, uncontrolled diabetes, or postmenopausal osteoporosis; 3) had a history of periodontal therapy; or 4) received antibiotics or long-term non-steroidal anti-inflammatory drugs within the past 3 months. Participants were enrolled in three groups according to criteria described by Ramseier et al.:22 1) a healthy/gingivitis group with $\leq 3-\mathrm{mm}$ clinical attachment level (CAL), no probing depth (PD) $\geq 4 \mathrm{~mm}$, and no radiographic alveolar bone loss; 2) a mild CP group with at least four sites with radiographic bone loss, PD $\geq 4 \mathrm{~mm}$, and $<30 \%$ of sites with CAL $>3 \mathrm{~mm}$; and 3) a moderate/severe CP group with at least four sites with radiographic bone loss, PD $\geq 4 \mathrm{~mm}$, and $>30 \%$ of sites with CAL $>3 \mathrm{~mm}$.

Table I.

\section{Patient Demographics and Clinical Characteristics}

\begin{tabular}{|c|c|c|c|c|c|}
\hline Characteristic & Overall & Healthy Group & Mild CP Group & Moderate/Severe CP Group & $P$ values \\
\hline Participants (n) & 57 & 8 & 31 & 18 & \\
\hline Females (n [\%]) & $31(54.4)$ & $7(87.5)$ & $20(64.52)$ & $4(22.2 \%)$ & \\
\hline Smokers (n [\%]) & $21(36.84)$ & I (12.5) & $9(29)$ & $11(61.11 \%)$ & $P_{r}=0.03$ \\
\hline Mean no. of teeth & 25 & 27 & 25 & 24 & \\
\hline Mean age (years) & 52.45 & 47.12 & 53.77 & 52.55 & 0.28 \\
\hline Sites with BOP (\%) & 54 & 20 & 58 & 66 & $<0.00$ । \\
\hline Sites sampled (n) & 1,336 & 210 & 717 & 409 & \\
\hline Mean \pm SD PD (mm) & 2.58 & $1.8 \pm 0.56$ & $2.66 \pm 1.14$ & $3.55 \pm 1.6$ & $<0.00$ । \\
\hline Sites with $P D \geq 4 \mathrm{~mm}$ & 16 & 0 & $12.6(8 \%)$ & $31.8(21 \%)$ & $<0.001$ \\
\hline Mean $\pm \mathrm{SD}$ CAL $(\mathrm{mm})$ & 2.12 & $0.8 \pm 0.86$ & $2.19 \pm 1.45$ & $3.6 \pm 1.98$ & $<0.001$ \\
\hline
\end{tabular}




\section{Clinical Measurements}

Interexaminer calibration was performed among examiners (HA, ML, and CK) on a periodic basis, and a $\kappa$ score of 0.8 or more was maintained throughout the study. All teeth except third molars were assessed for periodontal clinical measures. Clinical parameters, including PD, CAL, and bleeding on probing (BOP), were measured at six sites per tooth. Other clinical measures included dichotomous measures of plaque accumulation index (PI) and gingival redness index (GI) as described previously by Haffajee et al. ${ }^{23}$

\section{Whole Saliva Collection}

Unstimulated or resting whole saliva was collected from all participants at the beginning of the appointment by passive drooling into a graduated sterile tube. The collection was completed as soon as $2 \mathrm{~mL}$ whole saliva was collected or 15 minutes of sampling time elapsed. The samples were placed on ice, mixed with $20 \mu \mathrm{L}$ protease inhibitor cocktail, ${ }^{\ddagger}$ vortexed and aliquoted in equal quantities into six centrifuge tubes, and stored at $-80^{\circ} \mathrm{C}$ until additional analysis.

\section{Serum Collection}

Six milliliters of blood were drawn by a registered nurse via venipuncture and collected in serum separator tubes. The specimens were allowed to clot for 30 minutes and centrifuged for 4.5 minutes at $4,450 \mathrm{rpm}$, and then the serum was aliquoted into six cryovials and stored at $-80^{\circ} \mathrm{C}$ until additional analysis.

\section{GCF Collection and Sampling}

GCF from the mesio-buccal site of each tooth was collected using paper strips. $§$ To minimize contamination, all clinically detectable supragingival plaque was removed, and the area was isolated with cotton rolls and gently air dried before sampling. During sampling, the paper strip was inserted below the gingival margin until slight resistance was felt, held in place for 30 seconds, and then removed. GCF volume was measured using a calibrated machine.l Strips that were contaminated with saliva, blood, or plaque were discarded. After volume determination, strips were stored in sterile collection tubes that were labeled with tooth numbers and contained a prealiquoted protease inhibitor cocktail and then stored at $-80^{\circ} \mathrm{C}$. Before analysis, the absorbed fluid was eluted from each strip into $135 \mu \mathrm{L}$ lysis buffer (100 $\mu \mathrm{L} 1 \mathrm{mM}$ phenylmethylsulfonyl fluoride in $1 \mathrm{~mL}$ radioimmunoprecipitation assay buffer) fl for a total elution volume of $1.235 \mathrm{~mL}$.

\section{Sample Analyses}

Enzyme-linked immunosorbent assays. Whole saliva and serum were used to quantify soluble Fas (sFas), FasL, and active caspase by quantitative sandwich enzyme-linked immunosorbent assay (ELISA)." Briefly, whole saliva and serum samples were thawed, $100 \mu \mathrm{L}$ supernatant was added in triplicate to ELISA plates, and the amounts of $\mathrm{sFas}$, FasL, and active caspase- 3 were measured at 540and 570-nm wavelengths using a spectrophotometer. For DNA fragmentation detection, the eluted GCF samples were assayed for histone-associated DNA fragments using a detection kit.**

Western immunoblotting. Western immunoblotting was used to detect the expression of specific apoptotic proteins in the GCF samples. Briefly, the $50-\mu \mathrm{L}$ eluted GCF sample was mixed with $50 \mu \mathrm{L}$ sample buffer $(950 \mu \mathrm{L}$ Laemmli sample buffer plus $50 \mu \mathrm{L} 2$-mercaptoethanol), ${ }^{\dagger \dagger}$ boiled for 5 minutes, and divided into three aliquots of equal volume. The molecular weight markers, controls (human oral squamous cell carcinoma cells treated with cisplatin), and equal volumes of samples (one tooth per well) were loaded onto $10 \%$ to $12 \%$ sodium dodecyl sulfate polyacrylamide gels and electrophoretically resolved under standard conditions. Next, the proteins were transferred onto polyvinylidene difluoride membranes $^{\text {}}{ }^{\ddagger}$ using standard protocols. After transfer, the membranes were incubated for 45 minutes in Tris-buffered saline (TBS) starting block $\S \S$ to block non-specific protein binding sites. Membranes were washed three times for 10 minutes with TBS and polysorbate 20 (TBST), separately incubated with 1:400 dilution of mouse antihuman Fas, mouse antihuman FasL, and mouse antihuman caspase- 3 overnight at $4{ }^{\circ} \mathrm{C}$, and then washed in TBST three times for 10 minutes each.|l| Blots were incubated with horseradish peroxidase-labeled antimouse immunoglobulin $G$ for 2 hours at room temperature, and chemiluminescent peroxidase substrate IfI $^{\text {was }}$ applied according to the instructions of the manufacturer. Membranes were briefly exposed to radiographic film, and densities of bands were scanned and analyzed using a scanning densitometer and imaging software."\#

Variations in the volume and protein sample loaded were corrected by assessing the targeted apoptotic proteins using a binary scale. The presence of each protein band was scored by one independent

\footnotetext{
† P2714, Sigma-Aldrich, St. Louis, MO.

$\S$ Oraflow, Smithtown, NY.

Oraflow.

II Sigma-Aldrich.

\# R\&D Systems, Minneapolis, MN.

** Cell Death Detection ELISA kit PLUS, Roche Diagnostics, Indianapolis, IN.

$\dagger \dagger$ Bio-Rad, Hercules, CA

$\neq \ddagger$ Millipore, Billerica, MA

§§ Starting block T2 (TBS) blocking buffer 37543, Thermo Fishe Scientific, Waltham, MA.

Santa Cruz Biotechnology, Santa Cruz, CA

II ECL-Plus detection system, Pierce, Thermo Scientific, Rockford, IL.

\#\# ImageJ software, NIH, Bethesda, MD.
} 


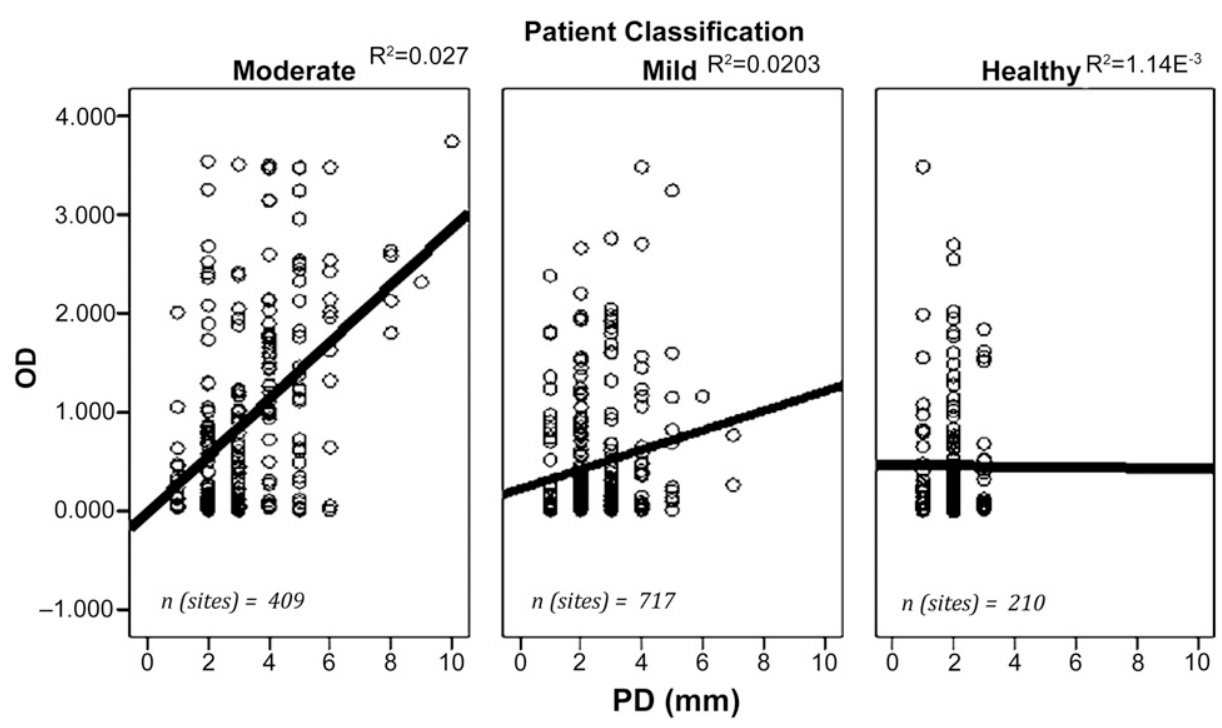

Figure I.

DNA fragmentation correlation of disease status with PD. The correlation coefficients comparing the optical density (OD) to PDs were analyzed by non-parametric two-tailed test to compare the mean coefficients between healthy, mild CP, and moderate/severe CP groups. A definite positive linear correlation can be observed between the OD values of DNA fragmentation and PD. This correlation increases in strength from the healthy/gingivitis group to the moderate/severe CP group. It was found that with a I-mm increase in PD, on average, $O D$ increases by 0.27 . tions were used to assess the relationship between the presence or absence of the apoptosis markers and PD, CAL, BOP, GI, and disease status. Because the outcome variable was binary, results were presented in terms of odds of presence (odds ratio [OR] of presence of apoptosis factor compared with its absence).

Data analysis was also performed using two participant groups based on the presence of traditional accepted signs of clinical disease activity (BOP, GI, and PD $\geq 5 \mathrm{~mm}){ }^{26-29} \mathrm{CAL}$ was excluded because it could represent past disease. Data were analyzed by included sites exhibiting both BOP and GI (Classification 1), as well BOP and $\mathrm{GI}$ and $\mathrm{PD} \geq 5 \mathrm{~mm}$ (Classification 2). observer (DD) and classified as negative or positive based on comparison with positive controls in accordance with the technique used by Bersano et al. ${ }^{24}$ The presence of each of Fas, FasL, and active caspase- 3 protein was counted if a band at a specific nuclear weight per antibody was detected at the molecular weight for each protein and was consistent with the positive control.

\section{Data Analyses}

The sample size calculation of 50 participants was based on a previous study comparing GCF among clinically healthy, mild/moderate $C P$, and severe $C P$ sites within patients. ${ }^{25}$ Data analysis was performed using a statistical package. *** The unit of analysis was tooth site, but the fact that sites were grouped within a patient was also accounted for. The level of significance was set at $P \leq 0.05$. All data were expressed as mean \pm SE for each factor.

Differences between groups were analyzed using $\chi^{2}$ correlation for binary demographic variables (sex, smoking status, and ethnicity), analysis of variance (ANOVA) for age, Kruskal-Wallis test to compare the mean proportions for BOP, GI, PD, and CAL, and regression analysis to account for confounding variables. GCF DNA fragmentation data were analyzed using mixed models for continuous outcomes. ANOVA was used to analyze data quantifying each of Fas, FasL, and caspase-3 proteins from both saliva and serum samples. Generalized estimating equa-

\section{RESULTS}

\section{Demographic Distribution of Patients and Clinical Parameters}

Fifty-seven patients were enrolled in the study: eight in the healthy/gingivitis group, 31 in the mild CP group, and 18 in the moderate/severe CP group. No statistical differences among groups were found for demographic variables except smoking status $(P=$ $0.03)$ and sex $(P=0.002$; Table 1$)$. Regression analysis was performed to account for the possible confounding effects, although this did not appear to influence the results. PD, AL, PI, BOP, and GI in the healthy group were significantly less than in the periodontitis groups $(P<0.001)$.

\section{Saliva Analyses}

Both sFasL and sFas were detected in all saliva samples, although caspase- 3 was not. sFasL concentrations in saliva ranged from 3.01 to $33.7 \mathrm{pg} / \mathrm{mL}$, with a mean value of $11.32 \pm 5.49 \mathrm{pg} / \mathrm{mL}$. sFas concentrations in saliva ranged from 15.9 to $2,748.31 \mathrm{pg} / \mathrm{mL}$, with a mean value of $708.4 \pm 769.6$ $\mathrm{pg} / \mathrm{mL}$. No significant differences were noted for sFas and sFasL among groups (see supplementary Fig. 1 in online Journal of Periodontology).

\section{Serum Analyses}

Five patients were excluded from serum analysis because of technical problems in acquiring a blood

*** SAS statistical package, SAS Institute, Cary, NC. 
sample. sFasL concentrations in serum ranged from 15.5 to $113.17 \mathrm{pg} / \mathrm{mL}$, with a mean value of $50.86 \pm$ $20.54 \mathrm{pg} / \mathrm{mL}$. sFas concentrations in serum ranged from 124.1 to $3,479.45 \mathrm{pg} / \mathrm{mL}$, with a mean value of $827.48 \pm 641.63 \mathrm{pg} / \mathrm{mL}$. No significant difference among groups for sFasL or sFas was noted (see supplementary Fig. 1 in online Journal of Periodontology). Caspase-3 was not detected in serum.

\section{GCF Analyses}

In GCF, PD and CAL were significantly correlated with DNA fragmentation $(P<0.001$; Figs. 1 and 2$)$. Increases in PD and CAL were analyzed using the basic unit of measurement, which was millimeters.
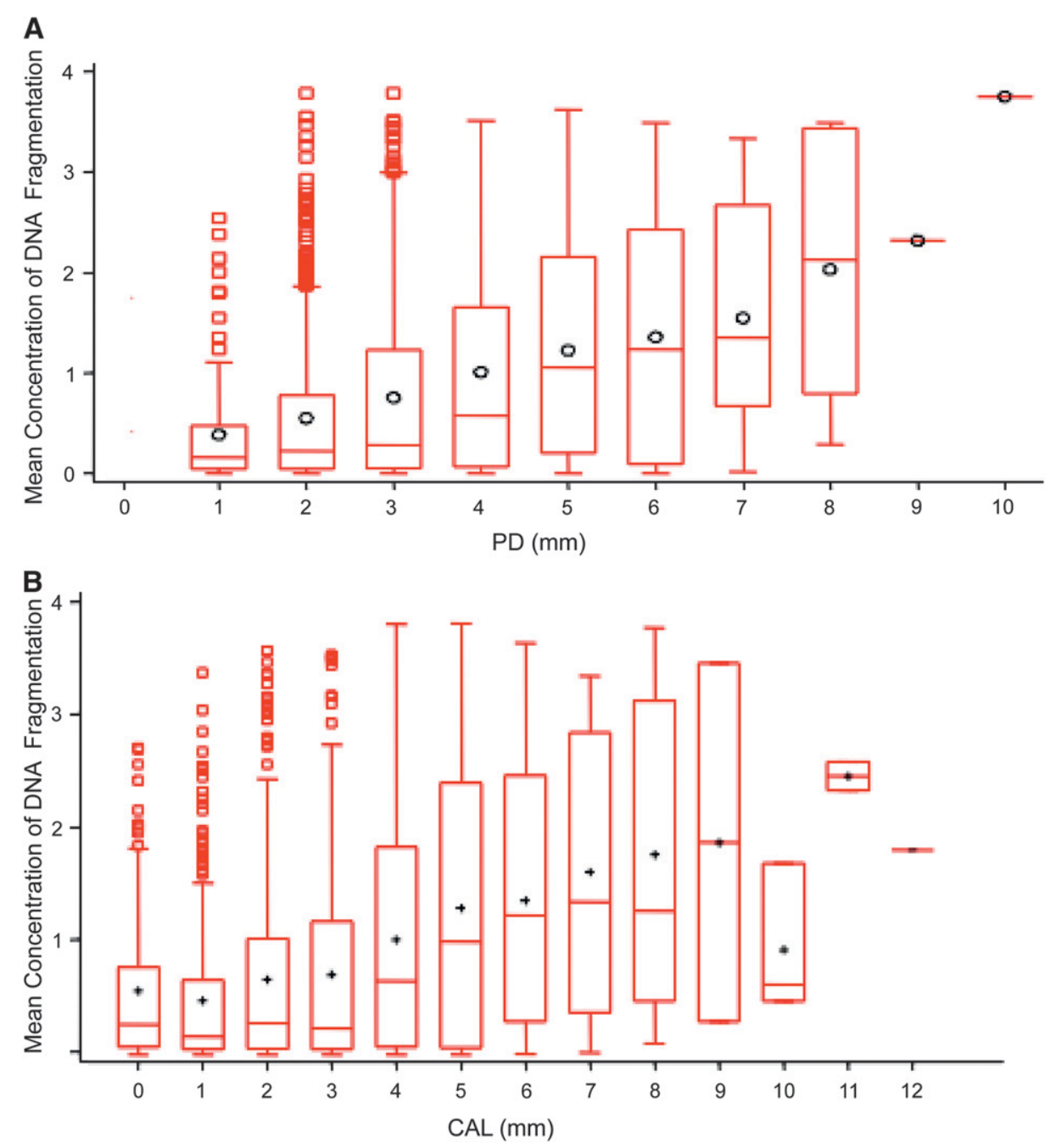

Figure 2.

Correlation of DNA fragmentation with PD and CAL. A) A box plot demonstrating the correlation of DNA fragmentation with PD. Overall, the mean concentration of DNA fragmentation in GCF increased as the PD increased $(P<0.001)$. Within a patient, a PD increase of I $\mathrm{mm}$ showed an average increase of 0.2 DNA fragmentation optical density $(O D)$ units $(P<0.001)$. B) A box plot demonstrating the correlation of DNA fragmentation with CAL. Overall, the mean concentration of DNA fragmentation in GCF increased as the attachment loss increased ( $P<0.001$ ) Within a patient, with a I-mm increase in CAL, there was an average increase of 0.12 OD units of DNA fragmentation $(P<0.001)$.
Within a patient, a 1 -mm increase in PD correlated with an average increase of 0.2 DNA fragmentation optical density (OD) units $(P<0.001$; Figs. 1 and $2 A)$. Similarly, with each $1-\mathrm{mm}$ increase in CAL, there was an average increase of 0.12 OD units of DNA fragmentation $(P<0.001$; Fig. $2 \mathrm{~B})$. A trend toward lower DNA fragmentation values was observed among healthy patients when compared with moderate/ severe CP patients $(-0.1505)$, but the difference was not significant (Table 2).

The odds of detecting apoptotic marker expression using Western blot analysis increased with every 1 -mm increase in PD (see supplementary Table 1 in online Journal of Periodontology). In addition, the frequency of biomarker expression increased as disease severity increased for all apoptosis factors except FasL (Table 3). FasL expression was significantly increased in both the mild and moderate/severe CP groups compared with healthy controls $(P=0.007$ and $P=$ 0.045 , respectively; Table 3 ). The presence of apoptosis factors Fas, procaspase, and active procaspase were significantly correlated with PD $(P<0.05$; Table 3$)$. In addition, there was a trend toward statistical significance for FasL and active FasL. For every 1$\mathrm{mm}$ increase in PD, there was a $19 \%, 17 \%$, and $27 \%$ greater odds that Fas, procaspase, and active caspase were detected at that site, respectively. Similarly, CAL was a statistically significant predictor for all apoptosis factors $(P<0.05$; Table 3$)$. For every $1-\mathrm{mm}$ increase in CAL, there was a $12 \%, 12 \%$, $16 \%, 9 \%$, and $18 \%$ greater odds that Fas, FasL, active FasL, procaspase, and active caspase could be detected at that site, respectively.

When inflammation was present (designated by Classification 1, which included sites positive for both BOP and GI), there was a statistically significant OR for detecting active FasL, procaspase, and active caspase in GCF $(P<0.05$; Table $3)$. When sites were analyzed 
for the presence of $\mathrm{BOP}, \mathrm{GI}$, and $\mathrm{PD} \geq 5 \mathrm{~mm}$ (Classification 2), a stronger association was noticed with respect to biomarker expression of Fas, active FasL, procaspase, and active caspase $(P<0.05$; Table 3$)$.

\section{DISCUSSION}

There is increasing evidence that apoptosis plays a role in the pathogenesis of periodontal disease. However, little is known about the release of apoptotic proteins into GCF, saliva, and serum during periodontal breakdown in patients. To the best of the

\section{Table 2.}

\section{Correlations Using Generalized Estimating Equations of DNA Fragmentation With Disease Status, PD, and CAL}

\begin{tabular}{l|c|c}
\hline Status & $T$ Values & $P_{r}>t$ \\
\hline Intercept & 0.35 & 0.73 \\
Healthy & -0.30 & 0.77 \\
Mild & 0.06 & 0.95 \\
Moderate/severe & 0.36 & 0.72 \\
CAL & 12.08 & $<0.001^{*}$ \\
PD & 10.91 & $<0.001^{*}$ \\
\hline
\end{tabular}

Output from the mixed ANOVA models correlating DNA fragmentation OD values with disease status, $\mathrm{PD}$, and CAL. $P r=$ probability.

* $P<0.05$, statistically significant. authors' knowledge, this study is the first to detect these apoptotic markers in GCF. In addition, this is the first investigation of these apoptotic molecules in the saliva and serum of periodontally diseased patients.

Apoptosis occurs as part of normal cell turnover in health but increases in response to challenges within the oral cavity. Periopathogenic bacteria directly promote apoptosis of epithelial cells and gingival fibroblasts, exacerbating periodontal breakdown. In addition, apoptosis of these cells triggers the release of proinflammatory cytokines, which further perpetuates the disease progression. ${ }^{30}$ Traditional methods of disease recognition, such as changes in radiographic bone height, may be less timely because it takes several months for bone loss to become apparent radiographically.

Apoptosis can be induced either intrinsically or extrinsically. The extrinsic pathway is most relevant for periodontium-associated cellular apoptosis caused by exposure to periodontal pathogens. This signaling pathway involves binding of Fas or tumor necrosis factor- $\alpha$ (TNF- $\alpha)$ and subsequent activation of caspase. ${ }^{31,32}$ Bacterially induced cellular apoptosis within the periodontium predominantly affects connective tissue (CT) cells. ${ }^{8}$ The majority of cells undergoing apoptosis are fibroblasts, although polymorphonuclear leukocytes also undergo a degree of delayed apoptosis. ${ }^{33}$ In contrast, some leukocytes, macrophages, or other inflammatory cells become apoptotic as a result of periopathogenic

Table 3.

Correlation Between the Presence of the Apoptotic Biomarkers in GCF (predictors) and PD, CAL, and GI (outcomes) Using Generalized Estimating Equations

\begin{tabular}{|c|c|c|c|c|c|c|}
\hline OR & PD & CAL & Mild Disease & Moderate/Severe Disease & Classification I & Classification 2 \\
\hline \multicolumn{7}{|l|}{ Fas } \\
\hline OR & 1.19 & 1.12 & 0.95 & 1.14 & 1.33 & 2.08 \\
\hline$P$ value & 0.001 & $<0.001$ & 0.98 & 0.81 & 0.05 & 0.01 \\
\hline \multicolumn{7}{|l|}{ FasL } \\
\hline OR & 1.11 & 1.12 & 5.54 & 3.65 & 1.25 & 1.55 \\
\hline$P$ value & 0.06 & 0.006 & 0.007 & 0.045 & 0.15 & 0.14 \\
\hline \multicolumn{7}{|c|}{ Active FasL } \\
\hline OR & 1.16 & 1.16 & 1.83 & 2.02 & 1.54 & 2.53 \\
\hline$P$ value & 0.06 & 0.004 & 0.434 & 0.224 & 0.002 & 0.01 \\
\hline \multicolumn{7}{|l|}{ Procaspase } \\
\hline OR & 1.17 & 1.09 & 1.62 & 1.62 & 1.35 & 3.18 \\
\hline$P$ value & 0.002 & 0.03 & 0.39 & 0.41 & 0.02 & 0.001 \\
\hline \multicolumn{7}{|c|}{ Active caspase } \\
\hline OR & 1.27 & 1.18 & 1.37 & 1.41 & 1.68 & 4.04 \\
\hline$P$ value & $<0.001$ & 0.001 & 0.62 & 0.60 & 0.001 & $<0.001$ \\
\hline
\end{tabular}

Classification 1 = sites positive for $\mathrm{BOP}$ and GI; Classification 2 = sites positive for $\mathrm{BOP}, \mathrm{GI}$, and PD $\geq 5 \mathrm{~mm}$. 
bacterial interactions. ${ }^{8}$ An exception to this is Aggregatibacter actinomycetemcomitans $(A a)$, a virulent bacteria associated with aggressive periodontitis. Aa produces leukotoxin capable of inducing apoptosis in lymphocytes but sparing CT cells, such as fibroblasts. ${ }^{34}$

In a study of Aa-induced periodontitis in rats, factors known to induce apoptosis, such as TNF- $\alpha$ and FasL, were upregulated. ${ }^{35}$ This was associated with bone loss, indicating that apoptosis may have clinical relevance in periodontitis. In another study involving oral inoculation of $A a$ in rats with diabetes, inflammation and bone loss were associated with gingival epithelial and CT cell apoptosis. The authors postulated high TNF- $\alpha$ production, a potent inducer of apoptosis mediated by caspase 3 , as a potential mechanism to explain their results. ${ }^{36}$

The progression of periodontal disease is affected by apoptosis. Fibroblasts are the primary cell type affected by apoptosis, and their death leads to loss of CT strength and subsequent attachment loss. ${ }^{37,38}$ Epithelial cell apoptosis results in reduced integrity of the pocket barrier, allowing bacterial infiltration into the gingival tissues. ${ }^{39}$ This makes treatment more difficult, especially when tissue-invasive bacteria are involved.

Importantly, to the best of the authors' knowledge, this study is the first to demonstrate that apoptotic proteins and DNA fragments can be found in the GCF of patients with periodontal disease. Only one previous study was conducted in this area and reported non-detectable levels of sFas protein in the GCF of 36 patients with various degrees of periodontal disease. ${ }^{2}$ The ability to successfully detect apoptosis factors in the present study may be attributable to the insertion of the GCF paper strips to the base of the sulcus and the use of Western blotting instead of ELISA detection methods. Previous studies have demonstrated that the cells undergoing apoptosis at inflamed sites are located in the apical third of the sulcus, near the junctional epithelium. ${ }^{20,40}$

Because the presence of a group of traditional disease indicators is more accurate in determining inflammation and disease activity, ${ }^{26,41}$ sites were considered inflamed only when positive for both BOP and GI. Furthermore, it is well documented that the risk of periodontal breakdown increases in patients with residual PD $\geq 5 \mathrm{~mm} .{ }^{26}$ In this study, sites with PD $\geq 5 \mathrm{~mm}$ that are positive for GI and BOP simultaneously have significantly greater odds of apoptosis factor expression, with the exception of FasL. The findings for FasL expression may be attributed to the difference in sample size among groups. However, additional studies are needed to explain this difference.
At the site level, the presence of Fas, FasL, caspase-3, and DNA fragmentation were associated with clinical signs of periodontitis as well as inflammation. After controlling for sex and smoking, these were not confounding factors in the study, contrary to previous findings. ${ }^{42}$ At the patient level, the lack of significant differences in biomarker expression could be attributable to high patient variability, lack of specificity to host response, or influence of the host microflora, which was not evaluated.

Only one apoptosis factor, FasL, had statistically greater odds of being expressed in the mild CP group when compared with the healthy/gingivitis group. This could be attributable to dilution of the effect of diseased sites pooled with healthy sites because the number of pockets with PD $\leq 3 \mathrm{~mm}$ accounted for $\approx 75 \%$ of the sampled sites. Furthermore, it is possible that other systemic factors, such as inflammation in other parts of the body, could act as a confounding factor, also accounting for a lack of difference. It is noteworthy that the majority of studies evaluating apoptosis factors in GCF have limited their site selection to diseased sites in each patient ${ }^{2}$ rather than the mesial site of each tooth present as in the present study.

Apoptotic markers were also detected in shallow PDs, which might indicate that cells in these sites were undergoing apoptosis and tissue breakdown, or even simple homeostatic cell and tissue turnover at that time point. Also, the expression observed in these healthy sites and/or gingivitis sites might suggest that these sites appear to be progressing to periodontitis sites.

Unfortunately, because of the limited amount of GCF volume collected per site, normalization by protein concentration was not feasible. Thus, in the present study, despite efforts to standardize the potential factors that could affect the GCF samples, because of the limited sample volume available for analysis and the inability to find an appropriate control for normalization, qualitative data were reported instead of using concentrations.

The final pathway in apoptosis is initiated by caspase- 3 and ends with DNA fragmentation, which is a hallmark of apoptosis. One other group measured the degree of host $\beta$-globin DNA fragmentation in GCF and reported higher levels of DNA fragments in patients with periodontitis compared with gingivitis or healthy patients. ${ }^{43}$ These data are consistent with the positive correlation between DNA fragmentation with CAL and PD reported in the present study.

Serum sampling was performed to validate the relationship between saliva and serum with local disease in the oral cavity relative to circulating levels of factors associated with apoptosis. Mean concentrations of 
sFas and sFasL in serum were greater than the mean concentration in saliva, in accordance with other studies, ${ }^{44,45}$ suggesting that the apoptotic proteins present in serum might have an additional systemic contribution. The effect of factors expressed from the small fraction of sites undergoing apoptosis might be reduced or diluted in the larger volume of saliva, which might explain the lack of correlation among study groups.

Caspase- 3 has been shown in the literature to be increased in the serum of patients suffering from hepatitis $C,{ }^{18,46}$ cancer, ${ }^{47}$ rheumatoid arthritis, ${ }^{48}$ and heart disease. ${ }^{49}$ Another study demonstrated that apoptotic factors in the GCF correlated directly with PD. ${ }^{50}$ However, in the present study, caspase- 3 was observed in detectable levels in GCF and not detected in saliva and serum, which indicates that caspase- 3 is activated and secreted locally by the mesenchymal cells, such as gingival and periodontal ligament fibroblasts and/or macrophages and neutrophils, into the GCF and not derived from systemic contribution or saliva contamination. It also suggests that caspase- 3 might have a shorter half-life that is easily captured in GCF in which the cells are undergoing apoptosis rather than at distant sites in saliva or serum. Finally, the different methods used to detect caspase-3 in GCF compared with saliva and serum may partially explain the reason for this variability.

To date, no single protein biomarker has proven to be reliable in the clinical setting. Given the complex nature of periodontal disease, it is unlikely that a sole factor exists for disease detection and disease prediction, and the examination of multiple apoptosis factors or clusters at once might be a more appropriate method for disease status determination. ${ }^{51,52}$ The findings in this study may give insight into the role of apoptosis in periodontal disease pathogenesis and highlight the potential role of apoptotic molecules in periodontal disease prediction. This new knowledge may lead to strategies to prevent or modulate periodontal disease, including the development of agents to limit or modify apoptosis.

\section{CONCLUSIONS}

This pilot study demonstrates that factors associated with apoptosis are detected in GCF. Nevertheless, one should exercise caution in interpreting these promising findings. Additional studies involving longitudinal assessments with larger populations and the use of more sensitive methods for detection are needed to confirm the findings.

\section{ACKNOWLEDGMENTS}

This work was supported by National Institutes of Health Grant R01-DE013725, Clinical and Transla- tional Science Awards Grant UL1RR024986, National Center for Research Resources Grant UL1RR024986, and Delta Dental Foundation (to YK). The authors thank Christopher Fenno, William Giannobile, and Tae-Ju Oh for helpful advice and assistance. The authors report no conflicts of interest related to this study.

\section{REFERENCES}

1. Yamamoto S, Mogi M, Kinpara K, et al. Anti-proliferative capsular-like polysaccharide antigen from Actinobacillus actinomycetemcomitans induces apoptotic cell death in mouse osteoblastic MC3T3-E1 cells. $J$ Dent Res 1999;78:1230-1237.

2. Mogi M, Otogoto J, Ota N, Inagaki H, Minami M, Kojima $\mathrm{K}$. Interleukin 1 beta, interleukin 6, beta 2-microglobulin, and transforming growth factor-alpha in gingival crevicular fluid from human periodontal disease. Arch Oral Biol 1999;44:535-539.

3. Cohen JJ. Programmed cell death and apoptosis in lymphocyte development and function. Chest 1993; 103(Suppl. 2):99S-101S.

4. Thompson CB. Apoptosis in the pathogenesis and treatment of disease. Science 1995;267:1456-1462.

5. Arnold R, Seifert M, Asadullah K, Volk HD. Crosstalk between keratinocytes and T lymphocytes via Fas/Fas ligand interaction: Modulation by cytokines. JImmunol 1999;162:7140-7147.

6. Griffith TS, Brunner T, Fletcher SM, Green DR, Ferguson TA. Fas ligand-induced apoptosis as a mechanism of immune privilege. Science 1995;270:1189-1192.

7. Yoshioka C, Muraki Y, Fukuda J, Haneji T, Kobayashi N. Identification of the Fas antigen in human gingiva. J Dent Res 1996;75:1353-1357.

8. Koulouri O, Lappin DF, Radvar M, Kinane DF. Cell division, synthetic capacity and apoptosis in periodontal lesions analysed by in situ hybridisation and immunohistochemistry. J Clin Periodontol 1999;26: 552-559.

9. Krajewska M, Wang HG, Krajewski S, et al. Immunohistochemical analysis of in vivo patterns of expression of CPP32 (Caspase-3), a cell death protease. Cancer Res 1997;57:1605-1613.

10. Li NL, Nie H, Yu QW, et al. Role of soluble Fas ligand in autoimmune diseases. World J Gastroenterol 2004;10: 3151-3156.

11. Miret C, Font J, Molina R, et al. Relationship of oncogenes (sFas, Bcl-2) and cytokines (IL-10, alfaTNF) with the activity of systemic lupus erythematosus. Anticancer Res 2001;21:3053-3059.

12. Ohtsuka T, Hamada M, Sasaki O, et al. Clinical implications of circulating soluble Fas and Fas ligand in patients with acute myocardial infarction. Coron Artery Dis 1999;10:221-225.

13. Okura T, Watanabe S, Jiang Y, et al. Soluble Fas ligand and atherosclerosis in hypertensive patients. J Hypertens 2002;20:895-898.

14. Kondera-Anasz Z, Mielczarek-Palacz A, Sikora J. Soluble Fas receptor and soluble Fas ligand in the serum of women with uterine tumors. Apoptosis 2005;10:11431149.

15. Ugurel S, Rappl G, Tilgen W, Reinhold U. Increased soluble CD95 (sFas/CD95) serum level correlates with poor prognosis in melanoma patients. Clin Cancer Res 2001; 7:1282-1286. 
16. Ichikura T, Majima T, Uchida T, Okura E, Ogawa T, Mochizuki H. Plasma soluble Fas ligand concentration: Decrease in elderly men and increase in patients with gastric carcinoma. Oncol Rep 2001;8:311-314.

17. Ateş A, Kinikli G, Turgay M, Duman M. The levels of serum-soluble Fas in patients with rheumatoid arthritis and systemic sclerosis. Clin Rheumatol 2004;23:421 425.

18. Bantel H, Lügering A, Poremba $C$, et al. Caspase activation correlates with the degree of inflammatory liver injury in chronic hepatitis $\mathrm{C}$ virus infection. Hepatology 2001;34:758-767.

19. Kobayashi T, Okamoto K, Kobata T, Hasumuna T, Nishioka K. Apomodulation as a novel therapeutic concept for the regulation of apoptosis in rheumatoid synoviocytes. Curr Opin Rheumatol 1999;11:188193.

20. Tonetti MS, Cortellini D, Lang NP. In situ detection of apoptosis at sites of chronic bacterially induced inflammation in human gingiva. Infect Immun 1998;66: 5190-5195.

21. Bantel H, Beikler T, Flemmig TF, Schulze-Osthoff K. Caspase activation is involved in chronic periodontitis. FEBS Lett 2005;579:5559-5564.

22. Ramseier CA, Kinney JS, Herr AE, et al. Identification of pathogen and host-response markers correlated with periodontal disease. J Periodontol 2009;80:436-446.

23. Haffajee AD, Socransky SS, Goodson JM. Comparison of different data analyses for detecting changes in attachment level. J Clin Periodontol 1983;10:298-310.

24. Bersano A, Fiorini M, Allaria S, et al. Detection of CSF 14-3-3 protein in Guillain-Barré syndrome. Neurology 2006;67:2211-2216.

25. Huynh QN, Wang S, Tafolla E, et al. Specific fibronectin fragments as markers of periodontal disease status. J Periodontol 2002;73:1101-1110.

26. Lang NP, Tonetti MS. Periodontal risk assessment (PRA) for patients in supportive periodontal therapy (SPT). Oral Health Preu Dent 2003;1:7-16.

27. Badersten A, Nilvéus R, Egelberg J. Scores of plaque, bleeding, suppuration and probing depth to predict probing attachment loss. 5 years of observation following nonsurgical periodontal therapy. J Clin Periodontol 1990;17:102-107.

28. Claffey N, Nylund K, Kiger R, Garrett S, Egelberg J. Diagnostic predictability of scores of plaque, bleeding, suppuration and probing depth for probing attachment loss. $31 / 2$ years of observation following initial periodontal therapy. J Clin Periodontol 1990;17:108-114.

29. Kinney JS, Morelli T, Braun T, et al. Saliva/pathogen biomarker signatures and periodontal disease progression. J Dent Res 2011;90:752-758.

30. Guggenheim B, Gmür R, Galicia JC, et al. In vitro modeling of host-parasite interactions: The "subgingival" biofilm challenge of primary human epithelial cells. BMC Microbiol 2009;9:280.

31. Weinrauch Y, Zychlinsky A. The induction of apoptosis by bacterial pathogens. Annu Rev Microbiol 1999;53: 155-187.

32. Böhme L, Rudel T. Host cell death machinery as a target for bacterial pathogens. Microbes Infect 2009;11:10631070.

33. Gamonal J, Sanz M, O'Connor A, et al. Delayed neutrophil apoptosis in chronic periodontitis patients. $J$ Clin Periodontol 2003;30:616-623.

34. Tsai CC, McArthur WP, Baehni PC, Hammond BF, Taichman NS. Extraction and partial characterization of a leukotoxin from a plaque-derived Gram-negative microorganism. Infect Immun 1979;25:427-439.

35. Li Y, Messina C, Bendaoud M, Fine DH, Schreiner H, Tsiagbe VK. Adaptive immune response in osteoclastic bone resorption induced by orally administered $\mathrm{Ag}$ gregatibacter actinomycetemcomitans in a rat model of periodontal disease. Mol Oral Microbiol 2010;25: 275-292.

36. Kang J, de Brito Bezerra B, Pacios S, et al. Aggregatibacter actinomycetemcomitans infection enhances apoptosis in vivo through a caspase-3-dependent mechanism in experimental periodontitis. Infect Immun 2012;80:2247-2256.

37. Liu R, Bal HS, Desta T, et al. Diabetes enhances periodontal bone loss through enhanced resorption and diminished bone formation. J Dent Res 2006;85:510 514.

38. Zappa U, Reinking-Zappa M, Graf H, Case D. Cell populations associated with active probing attachment loss. J Periodontol 1992;63:748-752.

39. Dickinson BC, Moffatt CE, Hagerty D, et al. Interaction of oral bacteria with gingival epithelial cell multilayers. Mol Oral Microbiol 2011;26:210-220.

40. Jarnbring F, Somogyi E, Dalton J, Gustafsson A, Klinge B. Quantitative assessment of apoptotic and proliferative gingival keratinocytes in oral and sulcular epithelium in patients with gingivitis and periodontitis. $J$ Clin Periodontol 2002;29:1065-1071.

41. Heitz-Mayfield LJ. Disease progression: Identification of high-risk groups and individuals for periodontitis. J Clin Periodontol 2005;32(Suppl. 6):196-209.

42. Suzuki N, Wakisaka S, Takeba Y, Mihara S, Sakane T. Effects of cigarette smoking on Fas/Fas ligand expression of human lymphocytes. Cell Immunol 1999;192: 48-53.

43. Thaweboon B, Laohapand $P$, Amornchat $C$, et al. Host beta-globin gene fragments in crevicular fluid as a biomarker in periodontal health and disease. J Periodontal Res 2010;45:38-44.

44. Nakamura H, Kawakami A, Izumi M, et al. Detection of the soluble form of Fas ligand ( $\mathrm{sFasL}$ ) and sFas in the saliva from patients with Sjögren's syndrome. Clin Exp Rheumatol 2005;23:915.

45. Imirzalioĝlu P, Uckan S, Alaaddinoĝlu EE, Haberal A, Uckan D. Cigarette smoking and apoptosis. J Periodontol 2005;76:737-739.

46. Bantel H, Lügering A, Heidemann J, et al. Detection of apoptotic caspase activation in sera from patients with chronic HCV infection is associated with fibrotic liver injury. Hepatology 2004;40:1078-1087.

47. Roth C, Pantel K, Müller V, et al. Apoptosis-related deregulation of proteolytic activities and high serum levels of circulating nucleosomes and DNA in blood correlate with breast cancer progression. BMC Cancer 2011;11:4

48. Liagre B, Vergne-Salle P, Leger DY, Beneytout JL. Inhibition of human rheumatoid arthritis synovial cell survival by hecogenin and tigogenin is associated with increased apoptosis, p38 mitogen-activated protein kinase activity and upregulation of cyclooxygenase2. Int J Mol Med 2007;20:451-460.

49. Agosto M, Azrin M, Singh K, Jaffe AS, Liang BT. Serum caspase-3 p17 fragment is elevated in patients with ST-segment elevation myocardial infarction: A novel observation. J Am Coll Cardiol 2011;57:220-221.

50. Ohshima M, Fujikawa K, Akutagawa H, Kato T, Ito K, Otsuka K. Hepatocyte growth factor in saliva: A 
possible marker for periodontal disease status. J Oral Sci 2002;44:35-39.

51. Taba M Jr, Kinney J, Kim AS, Giannobile WV. Diagnostic biomarkers for oral and periodontal diseases. Dent Clin North Am 2005;49:551-571, vi.

52. Loo JA, Yan W, Ramachandran P, Wong DT. Comparative human salivary and plasma proteomes. J Dent Res 2010;89:1016-1023.
Correspondence: Dr. Yvonne L. Kapila, Department of Periodontics and Oral Medicine, University of Michigan School of Dentistry, 1011 N. University Ave., Room 5223, Ann Arbor, MI 48109-1078. Fax: 734/763-5503; e-mail: ykapila@umich.edu.

Submitted February 10, 2013; accepted for publication November 14, 2013. 